\title{
Direct Questioning of Genital Symptoms: Increasing Opportunities for Identifying and Treating Sexually Transmitted Infections in Primary Health-care Settings
}

\author{
Ayesha B M Kharsany', May Mashego', Mukeliswe Mdlotshwa', Janet Froblich', Quarraisha Abdool Karim,2
}

\begin{abstract}
We investigated the validity of self-reporting of genital symptoms amongst rural women attending primary health care clinics in rural KwaZulu-Natal. Random samples of 226 women were interviewed to measure self-reporting (unprompted), prompted and pelvic examination findings of genital symptoms. Against the presence of any STI self-reporting (unprompted) of symptoms had a sensitivity of $46.1 \%$, specificity of $64.7 \%$, positive predictive value (PPV) of $80.0 \%$ and negative predictive value (NPV) of $28.0 \%$ compared to prompted symptoms which had a sensitivity of $78.5 \%$, specificity of $52.9 \%$, PPV of $80.4 \%$ and NPV of $50.0 \%$. The agreement between self-reporting (unprompted) and prompted symptoms was 0.54 (Kappa statistic). Our results suggest that in rural areas, by prompting women with a simple set of questions, the identification and treatment of STIs in this population would be enhanced, leading to better reproductive health outcomes including reduction of risk of infection with HIV. (Rev Afr Santé Reprod 2006; 10[2]:105-112)
\end{abstract}

\section{RÉSUMÉ}

Interrogation directe des symptômes génitaux: Accroissement des opportunités pour l'identification et le traitement des infections sexuellement transmissibles dans le cadre des services médicaux primaires. Nous avons étudié la validité de signaler soi-même les symptômes génitaux parmi les femmes rurales qui fréquentaient les cliniques des services médicaux primaires dans KwaZulu-Natal rural. Les échantillons aléatoires de 226 femmes ont été interviewés afin de mésurer l'auto-signalisation (non poussés), la signalisation poussés et les résultats des examens de symptômes génitaux. Par rapport à la présence des IST, la signalisation de soi-mème (non-poussée) des symptômes avait une sensitivité de 46,1\%, une spécificité de $64,7 \%$ une valeur prévisionnelle positive (VPP) de $80,0 \%$ et une valeur prévisionnelle négative (VPN) de 28,0\% comparée aux symptômes poussés qui avaient une sensitivité de 78,5\%, une spécificité de 52,9\%, VPP de 80,4\% et VPN de 50,0\%. La correspondance entre la signalisation, de soi-même (nonpoussée) et les symptômes poussés était de 0,54 (statistiques Kappa). Nos résultats ont montré que dans les régions rurales, si l'on pousse les femmes à l'aide d'une série de questions, l'identification et le traitement des IST au sein de cette population seront mise en valeur, ce qui menera aux meilleurs résultats par rapport à la santé de reproduction y compris la réduction du risque d'être atteint du VIH. (Rev Afr Santé Reprod 2006; 10[2]:105-112)

KEY WORDS: self-reporting of genital symptoms, primary health care facility, rural setting, sexually transmitted infections, HIV infection

${ }^{1}$ Centre for the AIDS Programme of Research in South Africa (CAPRISA), Nelson R Mandela School of Medicine, University of KwaZulu-Natal, Durban, South Africa. ${ }^{2}$ Division of Epidemiology, Joseph Mailman School of Public Health, Columbia University, New York, USA

Correspondence to: ABM Kharsany CAPRIS A 2 2n Floor Doris Duke Medical Research Institute Nelson R Mandela School of Medicine, Faculty of Health Sciences, University of KwaZulu-Natal, Private Bag 7, Congella, 4013, South Africa.Tel:27312604558 Fax: 27312604566 e-mail: kharsany@ukzn.ac.za 


\section{Introduction}

Sub-Saharan Africa bears the largest burden of sexually transmitted infections (STIs), with almost $35 \%$ of the 340 million curable STI cases occurring amongst women, children and youth ${ }^{1}$. STIs are important causes of gynaecological and pregnancy-related morbidity ${ }^{2,3}$ and their presence enhances the transmission of $\mathrm{HIV}^{4,5,6}$. Therefore the detection and correct management of STIs are critical for the prevention of STIs and HIV.

Data from several local studies have documented an alarmingly high burden of STIs amongst public health sector users in both urban and rural settings $7,8,9,10,11,12,13$. About 3 to $5 \%$ of women accessing public sector family planning (FP) and antenatal (AN) services have gonorrhoeae, chlamydial infection and syphilis $7,10,13,14,15$. Furthermore, trichomoniasis and bacterial vaginosis have been diagnosed in 15 to $50 \%$ of women $^{7,10,14}$. Finally, 15 to $40 \%$ of pregnant women are also infected with $\mathrm{HIV}^{13,16}$. These data indicate that young women accessing these facilities are at high risk of acquiring HIV infection, further exacerbated by asymptomatic and untreated sexually transmitted infections, which continue to act as reservoirs for transmi$\operatorname{ssion}^{8,11}$.

The transmission of HIV-1 in sub-Saharan Africa is mainly through heterosexual intercourse with strong epidemiologic evidence that STIs significantly increase the risk of acquiring and transmitting HIV-1 infection contributing to the rapid expansion of the HIV-1 epidemic ${ }^{4,5,7}$. This suggests that for any major impact on the spread of HIV, the prevention and control of STIs is vital.

Since the establishment of democracy in South Africa, a comprehensive package of health services is available at no cost, at all public sector primary health care (PHC) clinics. Services that form part of this package include contraceptive services, antenatal care, voluntary counseling and testing (VCT) for HIV infection, interventions to reduce mother to child transmission of HIV, cervical cancer screening, childhood immunization and growth monitoring services, treatments for tuberculosis, monitoring and management of chronic illnesses, syndromic management of STIs and access to male condoms. Whilst these services should be integrated in most settings service delivery remains vertical and independent, for example HIV risk reduction assessments, STI screening or VCT are not routinely offered to women seeking primary health care ${ }^{13}$.

The accurate detection of STIs is limited and as a consequence syndromic management to improve STI diagnosis and treatment in resourcepoor settings has been developed ${ }^{18}$. Most STI syndromic management protocols work well but rely on the recognition of symptoms by the infected person who consequently seeks medical treatment. The weakness of this approach is that many infected persons either have no symptoms, or have mild symptoms which are unnoticed or fail to recognize their symptoms ${ }^{8,11,18}$. True estimates of these asymptomatic infections vary considerably in different population groups. Women are also often dissuaded from seeking care to these clinics because of inconvenience, embarrassment and many do not perceive themselves at risk for STIs and HIV infection. Moreover, perceptions and understanding of genital tract signs and symptoms determine health care seeking practices, often resulting in a large proportion of STIs not being diagnosed and treated.

This study was undertaken to compare selfreporting (unprompted), prompted (direct questioning) and pelvic examination findings of genital symptoms with laboratory diagnosed sexually transmitted infections in clinic attendees in PHC settings.

\section{Material and Methods}

The study protocol was reviewed and approved by the Research Ethics Committee of the University of KwaZulu-Natal, Nelson R Mandela School of Medicine. All participants provided

African Journal of Reproductive Health Vol. 10 No.2 August 2006 
written informed consent to participate in the study. All interviews, informed consent, counseling sessions and administration of questionnaires were conducted in the local dialect.

All women attending public sector PHC clinics in a rural district of Kwa-Zulu- Natal midlands were informed of the study, including HIV testing in the context of pre- and post-test counseling, cervical cancer screening and provision of treatment for STIs. Those agreeing to provide written informed consent were included in the study.

\section{Study procedures}

A structured questionnaire was administered to 266 women to obtain socio-demographic information, reason for attending clinic, contraceptive history and past history of sexually transmitted infections. If women spontaneously reported on any genital symptoms (vaginal discharge, genital ulcers, lower abdominal pain, genital itching [pruritis], urinary symptoms) this was recorded as "self-reported" or unprompted. On direct questioning women were asked if they experienced each of these symptoms and these were reported as "prompted" genital symptoms. A comprehensive clinical and gynecological examination was performed which included palpation of the inguinal area for lymph nodes, speculum examination of the vagina, ectocervix and endocervix for the presence of any pathological discharge and genital ulcers. On a subset of women $(n=69)$ vaginal secretions were collected for the diagnosis of bacterial vaginosis ${ }^{19}$, T. vaginalis ${ }^{20}, \mathrm{~N}$. gonorrhoeae and $\mathrm{C}$. trachomatis (Becton Dickson Microbiology systems, USA). Peripheral blood was tested for HIV using Determine - HIV-1 ${ }^{\circledR}$ test (Abbott Diagnostics) and antibody positive sera confirmed using the CAPILLUS HIV 1/HIV 2 (Trinity Biotech, USA) test. Antibodies to syphilis were detected using the Rapid Plasma Reagin test (RPR) (Brewer Diagnostic Kit, BBL Microbiology Systems, Maryland, USA) and a Treponema pallidum haemagglutination test (TPHA) (Fujirebio). Women diagnosed with a clinical discharge and or genital ulcers were treated on the same day using the Department of Health's STI syndromic management guidelines ${ }^{21}$ and provided with condoms and contact cards for all sexual partners.

\section{Statistical Analysis}

The data were captured on EPI-INFO 6.03 (CDC Atlanta) and analysed using SPSS version 11.0 for windows. Sociodemographic, behavioural and clinical characteristics of participants were described using standard descriptive statistics. Prevalence for self-reported (unprompted), prompted genital symptoms, pelvic examination findings, bacterial vaginosis, trichomoniasis, chlamydial infection, gonorrhoeae, syphilis and HIV infection were determined. The effectiveness of self-reported (unprompted), prompted genital symptoms and pelvic examination findings were assessed in terms of sensitivity, specificity, positive and negative predictive values with any STI (trichomoniasis, chlamydial infection, gonorrhoeae, syphilis including bacterial vaginosis). We calculated the Cohen's Kappa statistic to assess the agreement between self- reported, prompted and pelvic examination findings.

\section{Results}

The demographic characteristics, past history, prevalence of STIs and HIV infection are shown in table 1 . Of the 266 women, $114(42.8 \%)$ were attending for family planning, 24 (10.6\%) for antenatal care and $88(38.9 \%)$ for minor ailments. The median (IQR [interquartile range]) age of the women was 24 (IQR 20-30) years; majority (190 / 84.1\%) reported being unmarried and less than $2 \%$ of women reported male condom use during coitus. Overall 145 (64.1\%) women reported having had a past history of at least one genital symptom of vaginal discharge (125; $55.3 \%)$, urinary symptoms $(87 ; 38.5 \%)$, and or genital ulcers $(60 ; 26.5 \%)$. Of these, $101(80.8 \%)$ 
had received treatment for vaginal discharge, 69 $(79.3 \%)$ for urinary symptoms and $52(86.6 \%)$ for genital ulcers.

\section{Current history of genital symptoms and pelvic examination findings}

Genital tract symptoms were frequent among participants with 88 (38.9\%) women self reporting (unprompted) vaginal discharge, lower abdominal pain, pruritis, urinary symptoms or genital ulcers (Table 2). When women were asked about specific symptoms (prompted), more 132 (58.4\%) women reported having symptoms of having vaginal discharge, lower abdominal pain, urinary symptoms, pruritis and genital ulcers (Table 2). On pelvic examination, inguinal lymphadenopathy and genital ulcers were present in $65(28.8 \%)$ and $11(4.9 \%)$ women respectively. The majority of women $(188 ; 83.2 \%)$ had clinical discharge ranging from mild in $73(32.3 \%)$, to moderate in $72(31.9 \%)$ to profuse in $43(19.0 \%)$ women. The discharge was malodorous in 102 (45.1\%). Additional signs associated with genital tract infections included lower abdominal pain (59; 26.1\%), cervical contact bleeding $(33 ; 14.6 \%)$ and adnexal tenderness $(33 ; 14.6 \%$ ) (Table 2).

\section{Validation of three methods to assess genital symptoms}

In a subset of women $(n=69)$, against the presence of STIs, self reporting (unprompted) of symptoms had a sensitivity of $46.1 \%$, specificity of $64.7 \%$, PPV of $80.0 \%$ and NPV of $28.0 \%$ compared with prompted symptoms, which had a sensitivity of $78.5 \%$, specificity of $52.9 \%$, PPV of $80.4 \%$ and NPV of $50.0 \%$. Pelvic examination had a sensitivity of $84.6 \%$, specificity of $12.0 \%$, PPV of $74.5 \%$ and NPV of $20.0 \%$ (Table 3). The estimated Cohen's Kappa statistic for selfreporting and prompted symptoms was 0.54 , whilst for self reporting and pelvic examination findings, it was 0.076 .

\section{Discussion}

Women utilizing PHC clinics in this community have an alarmingly high burden of HIV and other STIs. Detecting the presence of vaginal or cervical infections based on signs and symptoms remains a major challenge for the treatment of STIs. Timely diagnosis and treatment of STIs are therefore critical components in the prevention of the spread of STIs and HIV infection ${ }^{18}$. In South Africa efforts have been made to provide accessible health care through PHC clinics especially to women in rural communities. The provision of treatment for STIs and male condoms are freely available with extensive literature displayed on the walls providing information of STI signs and symptoms. Yet we found that less than a quarter of the women selfreported any genital signs and symptoms. Even if genital symptoms are present, women generally do not self report and therefore remain undiagnosed and untreated ${ }^{8,9}$ as confirmed by our data. On the other hand we found that on prompting for specific symptoms, about a third of the women reported having symptoms of vaginal discharge, lower abdominal pain, genital pruritis, urinary symptoms and or ulceration. However, on clinical examination more than $70 \%$ had clinical vaginal discharge. Most women consider the discharge to be part of their "normal" status, in particular, pregnant women consider the increased discharge to be normal for pregnancy, thus womens' perception of genital signs and symptoms remain low, often failing to seek medical advice ${ }^{8,9,10}$.

Studies have shown that the use of vaginal discharge alone as a predictor of cervical infection is problematic ${ }^{23}$. However, in this study a combination of genital symptoms of either vaginal discharge, genital ulceration, lower abdominal pain, urinary symptoms or genital itching were used which confirms that if one or more of these symptoms were reported, there was agreement between self-reporting of genital

African Journal of Reproductive Health Vol. 10 No.2 August 2006 
symptoms and prompted symptoms. The increasing sensitivity, high specificity and relatively high positive predictive value with prompted symptoms were successful in treating clients with STIs, suggesting that, by administering a simple set of questions to women attending PHC clinic would enhance the identification and treatment of STIs in this population leading to better reproductive health outcomes including reduction of risk of infection with HIV. Whilst the sensitivity of genital symptoms on pelvic examination increased, the specificity decreased and as such do not recommend the use of pelvic examination especially in busy clinic settings, which over diagnosed the occurrence of STIs and could substantially increase the time and cost of treating STIs $^{18}$. As part of a public health package women must be empowered with health education that can modify behaviour and hence enable them to recognize abnormal genital signs and symptoms and seek appropriate health care. We have subsequently provided simple information and education, encouraging patients to recognize and report on abnormal genital symptoms and to self report to health care providers for appropriate management. Furthermore, educational and training efforts should focus on health care providers in PHC settings to direct and extract key information on genital symptoms.

Syndromic management has been promoted as a practical and effective means to treat STIs, however, a major deficiency in its performance is that it has been developed as a diagnostic tool for symptomatic patients only ${ }^{22}$ and fails to identify women who remain asymptomatic or fail to seek treatment $t^{8,11,12}$. Moreover, because of the vertical delivery of health care many women are likely to remain undiagnosed, as seen in this study. There is broad agreement that STI management should be integrated and be part of the comprehensive reproductive and PHC services. These programmes should be well profiled to encourage women to recognize signs and symptoms and to seek treatment. Notwith- standing diagnostic limitations, and those related to asymptomatic presentation of STIs, in the context of syndromic management of STIs (which is standard of care in many developing countries) there are immense opportunities to proactively identify and treat STIs in women with no or very little additional cost.

In our study there was a high prevalence of sexually transmitted infections which is similar to those seen in many parts of sub-Saharan African countries $^{1}$, including rural South Africa ${ }^{8,9}$. Overall prevalence of bacterial vaginosis of $71.0 \%$ is higher than the 53\% reported for general women but lower than $85 \%$ amongst high risk women such as prostitutes and $70 \%$ amongst occasional sex traders ${ }^{23}$. Bacterial vaginosis has been well recognized to contribute to the development of ascending genital tract infections such as pelvic inflammatory disease ${ }^{24}$, endometritis and pregnancy related complications such as preterm labour, premature rupture of membranes, preterm deliver, chorioamniotis and post-partum endometritis ${ }^{2,3}$. Increasing evidence suggests that disturbances in the vaginal flora as in bacterial vaginosis play an important role in HIV transmission ${ }^{26}$. Thus treating for bacterial vaginosis in this population would clearly have an important public health impact. Vaginal trichomoniasis was diagnosed in a third of the women and remains consistently high. South African studies have shown that the prevalence ranges from $25 \%$ among FP attendees to as high as 52\% among AN attendees ${ }^{10,14}$. Although trichomoniaisis has been linked to low birth weight, recent studies in developing countries have found it to be associated with HIV infection, suggesting that trichomoniasis may increase the susceptibility to HIV infection ${ }^{27}$. The prevalence of chlamydial infection $(10 \%)$ was higher than gonorrhoeae $(2.9 \%)$. Gonorrhoeae appears to be the dominant aetiological agent amongst symptomatic patients whilst in asymptomatic patients the role of chlamydial infection may be important in subacute and/or latent infections ${ }^{10}$. 
In conclusion our study has shown that available services are inadvertently dispensed vertically and through an integrated approach of actively enquiring about genital symptoms, raising awareness and health education, will women be able to recognize abnormal genital symptoms, modify behaviour, improve health seeking practice and present timeously to the clinics for treatment. According to this study, physical examination for symptoms of STIs did not have any additional value. The effectiveness of this approach requires training, logistics, ongoing supervision and motivation of staff that would ultimately experience the benefits of such programs for their users.

Table 1: Socio-demographic characteristics and prevalence of sexually transmitted infections amongst women utilizing primary health care clinic in rural KwaZulu Natal

\begin{tabular}{lc}
\hline Median age (IQR) & 24 (IQR 20-30) \\
Marital status & $\mathbf{n}(\mathbf{\%})$ \\
$\quad$ Single & $190(84.1)$ \\
$\quad$ Married / Regular partner & $36(15.9)$ \\
Past History & $125(55.3)$ \\
$\quad$ Vaginal discharge & $60(26.5)$ \\
$\quad$ Genital ulcers & $87(38.4)$ \\
$\quad$ Urinary symptoms & \\
Prevalence of STIs (n=69) & $49(71.0)$ \\
$\quad$ Bacterial vaginosis & $21(30.4)$ \\
Trichomoniasis & $7(10.1)$ \\
$\quad$ Chlamydial infection & $2(2.9)$ \\
Gonorrhoeae & $3(4.3)$ \\
Syphilis & $52(75.4)$ \\
Any STI* & \\
Prevalence of HIV & $98(47.3)$ \\
HIV antibody (n=207)** & \\
* includes bacterial vaginosis & \\
** 19 women refused HIV testing &
\end{tabular}

Table 2: Reporting of genital signs and symptoms

\begin{tabular}{lccc}
\hline & $\begin{array}{c}\text { Unprompted } \\
\text { (Self Reporting) } \\
\mathbf{n}(\mathbf{\%})\end{array}$ & $\begin{array}{c}\text { Prompted } \\
\text { Reporting } \\
\mathbf{n}(\mathbf{\%})\end{array}$ & $\begin{array}{c}\text { Pelvic Examination } \\
\text { Findings } \\
\mathbf{n} \mathbf{( \% )}\end{array}$ \\
\hline Vaginal Discharge & $56(24.8)$ & $76(28.5)$ & $188(70.6)$ \\
Lower Abdominal Pain & $19(8.4)$ & $51(19.1)$ & $59(22.1)$ \\
Genital ulcers & $3(1.3)$ & $11(4.1)$ & $11(4.1)$ \\
Urinary symptoms & $10(4.4)$ & $38(14.2)$ & na \\
Pruritis & $13(5.8)$ & $42(15.7)$ & na \\
Inguinal lymphadenopathy & na & na & $33(24.4)$ \\
Adnexal tenderness & na & na & $33(12.4)$ \\
Cervical contact bleeding & na & na &
\end{tabular}


Table 3: Validity of self reported (unprompted), prompted and pelvic examination findings for genital symptoms

\begin{tabular}{lcccc}
\hline \multirow{2}{*}{ Genital symptoms } & \multicolumn{3}{c}{ Any Sexually Transmitted Infection* } \\
\cline { 2 - 5 } & $\begin{array}{c}\text { Sensitivity } \\
\%\end{array}$ & $\begin{array}{c}\text { Specificity } \\
\%\end{array}$ & $\begin{array}{c}\text { PPV } \\
\%\end{array}$ & $\begin{array}{c}\text { NPV } \\
\%\end{array}$ \\
\hline $\begin{array}{c}\text { Unprompted } \\
\text { (self reporting) }\end{array}$ & 46.1 & 64.7 & 80.0 & 28.0 \\
$\quad \begin{array}{l}\text { Prompted } \\
\text { Pelvic Examination } \\
\text { findings }\end{array}$ & 78.5 & 52.9 & 80.4 & 50.0 \\
*includes bacterial vaginosis & 84.6 & 12.0 & 74.5 & 20.7 \\
\hline
\end{tabular}

\section{REFERENCES}

1. World Health Organisation (WHO), Global Prevalence and Incidence of Selected curable Sexually Transmitted Infections: Overview and Estimates, Geneva: WHO, 2001.

2. Moodley P, Sturm AW. Sexually transmitted infections, adverse pregnancy outcome and neonatal infection. Semin Neonatol. 2000 ; 5 :255-69. Review.

3. Golderberg RL, Andrews WW, Yuan AC, MacKay HT, St Louis ME. Sexually transmitted diseases and adverse outcomes of pregnancy. Clin Perinatol. 1997; 24 : 23-41

4. Wasserheit JN. Epidemiological synergy: interrelationships between human immunodeficiency virus infection and other sexually transmitted diseases. Sex Transm Dis 1992; 19: 61-77.

5. Laga M. Epidemiology and control of sexually transmitted diseases in developing countries. Sex Transm Dis. 1994 ;21(2 Suppl):S45-50. Review.

6. Gray RH, Wawer MJ, Sweankambo NK, Serwadda D, Li C, Moultor LH, Lutalo T, Wabwire- Mangen F, Meehan MP, Ahmed S, Paxton L, Kiwanuka N, Nalugoda F, Korenromp EL and Quinn TC. Relative risk and population attributable fraction of incident HIV-1 associated with symptoms of sexually transmitted diseases in Rakai District, Uganda. .AIDS 1999, 13: 2113-2123.

7. Pham-Kanter GB, Steinberg MH, Ballard RC. Sexually transmitted diseases in South Africa. Genitourin Med. 1996, 72 :160-171.

African Journal of Reproductive Health Vol. 10 No.2 August 2006
8. Wilkinson D, Ndovela N, Harrison A, Lurie M, Connolly C, Sturm AW. Family Planning Services in developing countries: opportunities to treat asymptomatic and unrecognized genital tract infection. Genitourin Med.1997,73: 58-560.

9. Wilkinson D, Abdool Karim SS, Harrison A, Lurie M, Colvin M, Connolly C, Sturm AW. Unrecognized sexually transmitted infections in rural South African women: a hidden epidemic. Bull World Health Organ 1999; 77:22-28.

10. Kharsany ABM, Hoosen AA, Moodley J. Bacterial vaginosis and lower genital tract infections in women attending out-patient clinics at a tertiary institutions a developing community. J Obstet Gynaecol, 1997; 17: 171-175.

11. Sturm AW, Wilkinson D, Ndovela N, Bowen S, Connolly C. Pregnant women as a reservoir of undetected sexually transmitted diseases in rural South Africa: implications for disease control. Am J of Pub Health 1998; 88 1243-1245.

12. Colvin M, Abdool Karim SS, Connolly C, Hoosen AA, Ntuli N. HIV-1 infection and asymptomatic sexually transmitted infections in a rural South African community. Int J STD AIDS 1998;9:548-550.

13. Frohlich JA, Abdool Karim Q, Mashego MM, Sturm AW, Abdool Karim SS. Family and antenatal clients utilising primary care facilities in rural South Africa: Opportunities for treating sexually transmitted infections and reducing HIV risk (in press). 
112 African Journal of Reproductive Health

14. O'Farrell N, Hoosen AA, Kharsany ABM, van den Ende J. Sexually transmitted pathogens in pregnant women in rural South African Community. Genitourin Med. 1989, 65: 276-280.

15. Qolohle DC, Hoosen AA, Moodley J, Smith AN, Mlisana KP. Serological screening for sexually transmitted infections in pregnancy: is there any value in re-screening for HIV-1 and syphilis at the time of delivery? Genitourin Med. 1995; 71:65-67.

16. Department of Health, RSA. Report: National HIV and Syphilis antenatal sero-prevalence survey in South Africa 2003, 2004

17. Laga M, Nzila N, Goeman J. The interrelationship of sexually transmitted diseases and HIV infection: implications for the control of both epidemics in Africa. AIDS. 1991;5 Suppl 1:S55-63. Review.

18. Mayaud P, Mabey D. Approaches to the control of sexually transmitted infections in developing countries: old problems and modern challenges. Sex Transm Infect. 2004; 80:174-82.

19. Nugent RP, Krohn MA, Hillier SL. Reliability of diagnosing bacterial vaginosis is improved by a standardized method of Gram stain interpretation. J Clin Microbiol. 1991; 29:297-301.

20. Paterson BA, Tabrizi SN, Garland SM, Fairley CK, Bowden FJ. The tampon test for trichomoniasis: a comparison between conventional methods and a polymerase chain reaction for Trichomonas vaginalis in women. Sex Transm Infect. 1998, 74:136-139.

21. Department of Health, Directorate of HIV/AIDS and STDs. Training manual for the management of a person with a sexually transmitted disease. Pretoria: Department of Health;1999
22. Vuylsteke B. Current status of syndromic management of sexually transmitted infections in developing countries. Sex Transm Infect. 2004; 80 :333-4.

23. Behets F, Andriamiadana J, Rasamilalao D, Ratsimbazafy N, Randrianasolo D, Dallabetta G, Cohen M. Sexually transmitted infections and associated socio-demographic and behavioural factors in women seeking primary care suggest Madagascar's vulnerability to rapid HIV spread. Trop Med Int Health. 2001 ; 6 :202-11.

24. Ness RB, Hillier SL, Kip KE, Soper DE, Stamm CA, McGregor JA, Bass DC, Sweet RL, Rice P, Richter HE. Bacterial vaginosis and risk of pelvic inflammatory disease. Obstet Gynecol. 2004; 104 :761-9.

25. Haggerty CL, Hillier SL, Bass DC, Ness RB; PID Evaluation and Clinical Health study investigators. Bacterial vaginosis and anaerobic bacteria are associated with endometritis. Clin Infect Dis. 2004; 39: $990-5$.

26. Taha TE, Hoover DR, Dallabetta GA, Kumwenda NI, Mtimavalye LAR, Yang LP, Liomba GN, Broadhead RL, Chiphangwi JD, Miotti PG. Bacterial vaginosis and disturbances of vaginal flora: association with increased acquisition of HIV. AIDS. 1998;12: 1699 - 1706.

27. Buve A, Weiss HA, Laga M, Van Dyck E, Musonda R, Zekeng L, Kahindo M, Anagonou S, Morison L, Robinson NJ, Hayes RJ; Study Group on Heterogeneity of HIV Epidemics in African Cities. The epidemiology of trichomoniasis in women in four African cities. AIDS. 2001;15 Suppl 4:S89-96. 